\title{
Steel Fiber Volume Fraction and Splitting Tensile Strength of Steel Fiber Reinforced Concrete
}

\author{
Tingyi Zhang 1, 2, a, Wanzeng Song 1,2, Guanghe Zheng ${ }^{1,2}$, Haiting Song 1,2, \\ Min Wei ${ }^{1,2}$, Jing Shao ${ }^{1,2}$ and Yonghai Zhou ${ }^{1,2}$ \\ ${ }^{1}$ Yellow River Institute of Hydraulic Research, Zhengzhou 450003, China; \\ ${ }^{2}$ Research Center on Levee Safety \& Disaster Prevention, the Ministry of Water Resources, \\ Zhengzhou, 450003, China.
}

azty0760@126.com

\begin{abstract}
Keywords: Steel fiber; steel fiber volume fraction; steel fiber reinforced concrete; splitting tensile strength.
\end{abstract}

\begin{abstract}
In this paper, the effect of the steel fiber volume fraction upon the splitting tensile strength of steel fiber reinforced concrete (SFRC) was studied. The results show that steel fibers can improve splitting tensile strength of concrete. As the steel fiber volume fraction increases, the splitting tensile strength of SFRC and increment ratio increase. The splitting tensile strength of SFRC is related to the section characteristic of the specimen.
\end{abstract}

\section{Introduction}

Concrete is a man-made material, and there are micro cracks in it before bearing its loads. The damage and failure of the concrete structure are also related to these micro cracks. Adding steel fibers to concrete is an effective way to increase tensile strength of concrete and the ability of resistance to cracking and crack propagation. Steel fiber reinforced concrete (SFRC) is a composite material made with cement, aggregate, additive, and incorporating discrete discontinuous steel fibers. Steel fibers randomly distribute and are able to hold the matrix together like a bridge across the crack. Khalaj and Nazari studied the split tensile strength of high strength self-compacting concrete incorporating randomly oriented steel fibers [1]. Ramadoss and Nagamani researched the relationship between splitting tensile strength and flexural strength of the high-performance fiber reinforced concrete and obtained the equations for predicting the splitting tensile strength of the high-performance fiber reinforced concrete [2]. Wang and $\mathrm{Wu}$ investigated the splitting tensile strength of carbon fiber and steel fiber reinforced concrete and the obtained results showed that the splitting tensile strength of carbon fiber reinforced concrete was much smaller than that of SFRC [3]. Zhao et al. observed the tensile strength of the SFRC was enhanced more by steel fibers with a higher aspect ratio, since this improves the fiber-matrix bond. Some researchers presented formulae to calculate tensile strength of SFRC respectively $[4,5,6]$. The influencing steel fiber volume fraction on the splitting tensile strength of SFRC has received relatively little attention compared to studies on tensile strength test of SFRC. In this study, the cube specimens were used to investigate the effect caused by the steel fiber volume fraction $\left(\rho_{\mathrm{f}}\right)$ on the splitting tensile strength of SFRC.

\section{Experimental design and method}

\subsection{Materials.}

Grade 42.5 ordinary Portland cement was used in this study. The fine aggregate was natural river sand with a fineness modulus of 3.39. The coarse aggregate used was crushed limestone with maximum sizes of $20 \mathrm{~mm}$. The fiber used was plain steel fiber with a aspect ratio (ratio between fiber length and its equivalent diameter) of 34 and with $\rho_{\text {f }}$ of $0.5 \%, 1.0 \%, 1.5 \%$ and $2.0 \%$. The water to be 
mixed was local tap water.FDN-1 high efficiency water reducing agent with $1.0 \%$ cement dosage was also used. The mix proportions used for the manufacture of specimens are presented in Table 1.

Table 1. Mix proportion.

\begin{tabular}{|c|c|c|c|c|}
\hline Components \& characteristics & $\mathrm{A}_{1}$ & $\mathrm{~A}_{2}$ & $\mathrm{~A}_{3}$ & $\mathrm{~A}_{4}$ \\
\hline Cement $42.5\left(\mathrm{~kg} / \mathrm{m}^{3}\right)$ & 520 & 547 & 573 & 600 \\
\hline Sand $\left(\mathrm{kg} / \mathrm{m}^{3}\right)$ & 710 & 696 & 682 & 668 \\
\hline Coarse aggregate $(\leq 20 \mathrm{~mm})\left(\mathrm{kg} / \mathrm{m}^{3}\right)$ & 1065 & 1044 & 1023 & 1002 \\
\hline Water $\left(\mathrm{kg} / \mathrm{m}^{3}\right)$ & 156 & 164 & 172 & 180 \\
\hline Steel fiber $\left(\mathrm{kg} / \mathrm{m}^{3}\right)$ & 39.3 & 78.6 & 117.9 & 157.2 \\
\hline$\rho_{\mathrm{f}}(\%)$ & 0.5 & 1.0 & 1.5 & 2.0 \\
\hline$W / C$ & 0.30 & 0.30 & 0.30 & 0.30 \\
\hline
\end{tabular}

\subsection{Specimens.}

In this study, a series of cube specimens with the size of $150 \times 150 \times 150 \mathrm{~mm}$ was used to determine the splitting tensile strength of SFRC $\left(f_{\mathrm{ft}}\right)$. The cube specimens were designed according to test methods for physical-mechanical properties of fiber reinforced concrete in CECS 13:2009[7].

The specimens were cured in a closed curing room at relative humidity of $95 \%$ and controlled temperature $20 \pm 2^{\circ} \mathrm{C}$ for $28 \mathrm{~d}$ in order to allow all the mixes to undergo better hydration.

In order to objectively determine the effect of $\rho_{\mathrm{f}}$ on $f_{\mathrm{ft}}$ of SFRC, the concrete specimens, which were in contrast with the SFRC specimen, were cast. The batching proportion of concrete was the same as that of SFRC, but the former did not include steel fiber. According to the method above, the effect of the variation of matrix concrete on the test results can be eliminated. In this study, the increment ratio was used to reflect the effect of steel fiber on $f_{\mathrm{ft}}$ in Table 2 . The increment ratio is defined as the ratio of $f_{\mathrm{ft}}$ of SFRC to that of corresponding plain concrete, namely $f_{\mathrm{ft}}$ to $f_{\mathrm{t}}$ (the splitting tensile strength of concrete).

Table 2. Splitting tensile strength $\&$ increment ratio

\begin{tabular}{|c|c|c|c|c|}
\hline Splitting tensile strength \& increment ratio & $\mathrm{A}_{1}$ & $\mathrm{~A}_{2}$ & $\mathrm{~A}_{3}$ & $\mathrm{~A}_{4}$ \\
\hline$f_{\mathrm{ft}}$ & 5.48 & 5.75 & 6.15 & 6.85 \\
\hline$f_{\mathrm{t}}$ & 3.64 & 3.75 & 3.43 & 3.65 \\
\hline$f_{\mathrm{ft}} / f_{\mathrm{t}}$ & 1.51 & 1.53 & 1.79 & 1.88 \\
\hline
\end{tabular}

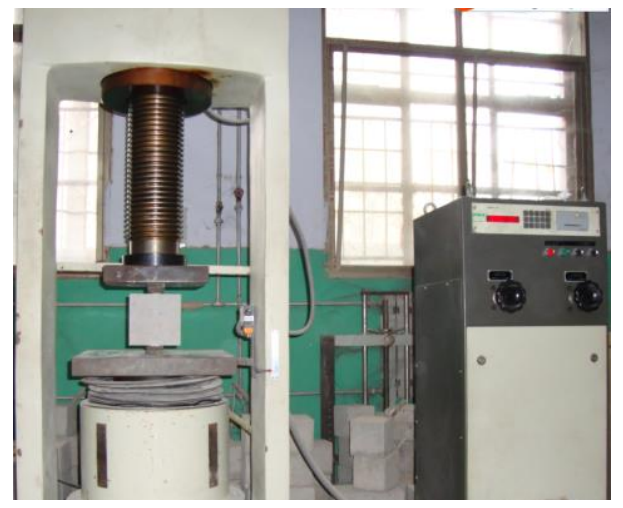

\subsection{Testing.}

Fig. 1 Test setup-loading system

Experimental tests were carried out by an electric-hydraulic testing machine with a maximum capacity of $3000 \mathrm{kN}$. The cube specimen was placed on the testing machine, as shown in Fig. 1.When load was introduced to the cube specimen, it was split along its middle parallel to the edges. After the specimen was destroyed, the failure load was record. $f_{\mathrm{ft}}$ and $f_{\mathrm{t}}$ can be computed as follow

$$
f=\frac{2 F}{\pi a^{2}}=0.637 \frac{F}{a^{2}}
$$


where $F$ is the failure load, and a is the dimension of the cube(here, $150 \mathrm{~mm})[7,8,9] . f$ was $f_{\mathrm{ft}}$ or $f_{\mathrm{t}}$, and computed as an average of five specimens in Table 2. The tests were load controlled, with a velocity of $1 \mathrm{kN} / \mathrm{s}$. A continual and consistent loading method was adopted, and the rate of loading was reduced properly when approaching failure.

\section{Results and discussion}

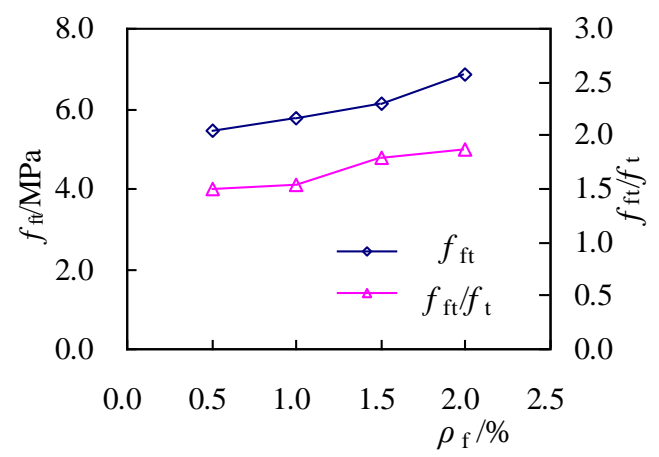

Fig.2. Effect of $\rho f$ on $\mathrm{fft}$ and $\mathrm{fft} / \mathrm{ft}$ of SFRC

Fig. 2 shows the change rules of the $f_{\mathrm{ft}}$ and $f_{\mathrm{ft}} / f_{\mathrm{t}}$ of SFRC, respectively, as $\rho_{\mathrm{f}}$ varies. From the figure, it can be seen that with the increasing of $\rho_{\mathrm{f}}, f_{\mathrm{ft}}$ and $f_{\mathrm{ft}} / f_{\mathrm{t}}$ tend to increase. When $\rho_{\mathrm{f}}$ increases from $0.5 \%$ to $2.0 \%$, fft increases $25 \%$ from 5.48 to $6.85 \mathrm{MPa}$ and $f_{\mathrm{ft}} / f_{\mathrm{t}}$ increases $24.5 \%$ from 1.51 to 1.88 . $f_{\mathrm{ft}} / f_{\mathrm{t}}$ with different $\rho_{\mathrm{f}}$ are beyond 1 , and mean value and maximum of $f_{\mathrm{ft}} / f_{\mathrm{t}}$ are 1.68 and 1.88 . Compared to the corresponding plain concrete, $f_{\mathrm{ft}}$ increases by more than $50 \%$, and maximum increase is $87.7 \%$, so steel fibers have a great effect on tensile property of concrete.

The tensile strength of concrete is closely related to the presence of any flaws and due to the rapid propagation of a single flaw or microcrack $[5,23]$. The failure of plain concrete begins in the inherent flaws such as microcrack. Compared to the plain concrete, the microcrack propagating in SFRC has to overcome resistance of steel fibers besides the bond between mortar and aggregate. In fact, because of the bond between steel fiber and matrix, even the propagation of a continuous crack will be slow, and in this course, the steel fibers can bridge across the crack and hold the matrix together. Thus, the steel fibers have an important effect on reinforcing concrete matrix, and this effect can be named as the bridging cracks effect. Therefore, $f_{\mathrm{ft}}$ is much higher than that of the corresponding plain concrete and $f_{\mathrm{ft}}$ $/ f_{\mathrm{t}}$ is beyond 1 .

\section{Summary}

Steel fiber is highly effective in increasing $f_{\mathrm{ft}} f_{\mathrm{ft}}$ increases by $50 \%$ as compared with that of the corresponding plain concrete. The variation of $\rho_{\mathrm{f}}$ from $0.5 \%$ to $1.0 \%$ to $1.5 \%$ to $2.0 \%$, the increase of $f_{\mathrm{ft}}$ is $4.93 \%, 6.96 \%$ and $11.38 \%$. $f_{\mathrm{ft}} / f_{\mathrm{t}}$ can be used to reflect reinforcement effect of steel fibers on $f_{\mathrm{ft}}$, and $f_{\mathrm{ft}} / f_{\mathrm{t}}$ is all beyond 1 .

\section{Acknowledgements}

The first and second authors contributed equally to this work. The authors would like to acknowledge the financial support received from the Research Foundation of Yellow River Institute of Hydraulic Research (Grant no. HKY-JBYW-2009-4) and the Research Foundation of Water Resource Public-Spirited Project (Grant no. 201501003). 


\section{References}

[1] G. Khalaj, A. Nazari. Modeling split tensile strength of high strength self-compacting concrete incorporating randomly oriented steel fibers and $\mathrm{SiO} 2$ nanoparticles. Compos Part B: Eng 43(2012)1887-92.

[2]P. Ramadoss, K. Nagamani. Tensile Strength \& Durability Characteristics of High Performance Fiber Reinforced Concrete. The Arabian J Sci Eng33 (2008) 577-82.

[3]C.Q.Wang, K.R.WU. Study on the Mechanical Properties of Carbon Fiber and Steel Fiber Concrete. J Build Mater 6(2003) 253-6.

[4]A.R. Khaloo, N.Kim. Mechanical Properties of Normal to High-Strength Steel Fiber-Reinforced Concrete. Cement Concr Res18 (1996)92-7.

[5]L.H.Xu, H.R.Xu, Y.Chi, Y.Y.Zhang. Experimental Study on Tensile Strength of Steel-Polypropylene Hybrid Fiber Reinforced Concrete. Adv Sci Lett 4(2011)911-6.

[6] D.Y. Gao, J. Zhao, J.Y. Tang. An experimental study on the behavior of fiber reinforced high strength concrete under splitting tension. China Civil Eng J 38(2005):21-6.

[7] Standard test methods for fiber reinforced concrete. CECS 13:2009. Beijing: China Planning Press.

[8] R.V.Balendran, F.P. Zhou, A.Nadeem, A.Y.T.Leung. Infuence of steel fibres on strength and ductility of normal and lightweight high strength concrete. Build Environ 37(2002)1361-7.

[9] G.Lin, J.Lu, Z.Wang, S.Xiao. Study on the reduction of tensile strength of concrete due to triaxial compressive loading history. Mag Concrete Res 54(2002)113-24.

[10] W.Khaliq, V.K.R.Kodur. Effect of High Temperature on Tensile Strength of Different Types of High-Strength Concrete. ACI Mater J 108(2011)394-402.

[11] H.Marzouk, Z.Chen. Fracture Energy and Tension Properties of High-Strength Concrete. J Mater Civil Eng 7(1995)108-16. 